\title{
Synthesis and characterisation of submicron silica particles from rice husk
}

Daniel Fernando Hincapié-Rojas Eng

Engineer, Laboratorio de Magnetismo y Materiales Avanzados,

Departamento de Física y Química, Universidad Nacional de Colombia,

Manizales, Colombia (Orcid:0000-0002-6648-5173)

Posidia Pineda-Gomez PhD

Doctor, Laboratorio de Magnetismo y Materiales Avanzados,

Departamento de Física y Química, Universidad Nacional de Colombia,

Manizales, Colombia; Facultad de Ciencias Exactas y Naturales, Universidad

de Caldas, Manizales, Colombia (corresponding author:

ppinegag@unal.edu.co) (Orcid:0000-0002-9753-066X)

\section{Andrés Rosales-Rivera PhD}

Doctor, Laboratorio de Magnetismo y Materiales Avanzados,

Departamento de Física y Química, Universidad Nacional de Colombia, Manizales, Colombia (Orcid:0000-0002-8451-1304)

Rice husk is considered an important silica source. In this work, microsilica particles were obtained by incineration of rice husk and milling of its ash. The synthesis process was carried out by incinerating the rice husk at $700^{\circ} \mathrm{C}$, followed by acid leaching in order to remove inorganic impurities and finally mechanical ball milling at $0,18,36$ and $72 \mathrm{~h}$ to reduce the particle size. Thermogravimetric analysis shows the thermal degradation of rice husk and elimination of organic components. The chemical composition was studied by X-ray fluorescence. The structural properties of silica were determined by X-ray diffraction. The morphological changes caused by mechanical milling were studied by scanning electron microscopy (SEM). The results indicate that between 150 and $450^{\circ} \mathrm{C}$, the organic material of the husk was released, and above $550^{\circ} \mathrm{C}$, ash with high silica content was obtained. Acid leaching increased the silica purity from 93.40 to $98.22 \%$. According to the X-ray diffraction analysis, the predominant phase was silica. The reduction in the crystallinity of silica samples was shown as an effect of mechanical milling while the particle size was reduced. The percentage of crystallinity decreased from 33.5 to $28.5 \%$ for after $72 \mathrm{~h}$ of milling. The SEM images showed that the particle size reduced with an increase in milling time, obtaining particle diameters smaller than $2.0 \mu \mathrm{m}$. The amorphous silica obtained from rice husk can be used for the production of highperformance silicon, silicon carbide, silicon nitride, silicon tetrachloride and zeolites.

\section{Introduction}

Rice is a fundamental part of the human diet. According to the Food and Agriculture Organization of the UN, the global production of rice in the year 2016 was 748.0 million t. ${ }^{1}$ As a result of rice production and refinement, each year, large amounts of husk are generated as a by-product or agricultural biomass. ${ }^{2}$ Its commercial cost is insignificant, but it is considered a natural silica source, which is used as fertilizer for land, ${ }^{3}$ as fuel in heat generation due to its high calorific value (approximately $13-16 \mathrm{MJ} / \mathrm{kg}$ ), ${ }^{4}$ for obtaining pozzolanic material ${ }^{5}$ and for biogas production. It can be also used as Portland cement additive $e^{6-8}$ and for the production of thermal energy, and it is considered as a source of lignocelluloses used in the preparation of bio-oil. ${ }^{9-11}$

About $20 \%$ of the volume of grain rice is husk, so that around 144 million $\mathrm{t}$ of rice husk (RH) is produced each year. ${ }^{12}$ In Colombia, about 793.880 metric $t$ of $\mathrm{RH}$ is produced per year. ${ }^{13}$ However, the accumulation of biomass has increased environmental concern. Using agricultural waste instead of conventional materials offers a very important environmental contribution; it helps to reduce the problems related to pollution and conservation of natural resources. ${ }^{14}$ This large amount of husk produced can generate problems related to solid wastes, and if it is not handled properly, it would increase the risk of fire, attract disease-carrying animals and even occupy large spaces in landfills or end up being dumped into water sources, causing release of methane (which is a greenhouse gas) during its decomposition and contaminating the environment and affecting people's health. ${ }^{2,15,16}$ Due to the rapid development of green technology, there is a growing tendency to produce materials from renewable sources. ${ }^{17}$ With the calcination of organic materials, thermal decomposition occurs and ash is obtained in a fine particle size; when mixed with lime, it can produce a material with binding properties, due to its pozzolanic activity. ${ }^{14}$

In the rice plant (Oryza sativa), silica that is stored in the husk enters in a soluble form, as a monosilicate acid, through the roots and it moves to the outer surface of the plant, where it becomes concentrated by evaporation and polymerisation and a membrane of silica and cellulose is formed. ${ }^{18}$ On the other hand, the RH contains about $75-90 \%$ organic matter (cellulose, lignin and hemicellulose), and the rest (10-25\%) corresponds to other inorganic elements such as silica and traces of elements (oxides). ${ }^{12,14,19}$ Of these inorganic components, silica represent about $94 \%$ of its weight, while the remaining $6 \%$ corresponds to oxides as calcium oxide $(\mathrm{CaO})$, potassium oxide $\left(\mathrm{K}_{2} \mathrm{O}\right)$, magnesium oxide $(\mathrm{MgO})$, aluminium oxide $\left(\mathrm{Al}_{2} \mathrm{O}_{3}\right)$, phosphorus pentoxide $\left(\mathrm{P}_{2} \mathrm{O}_{5}\right)$, manganese oxide $(\mathrm{MnO})$ and iron $(\mathrm{V})$ oxide $\left(\mathrm{Fe}_{2} \mathrm{O}_{5}\right){ }^{15}$ 
Heat treatment is used to reduce the organic compounds in $\mathrm{RH}$. Inorganic impurities or trace metals are removed by acid chemical treatment, in order to transform these impurities into soluble ions and remove them by filtration. ${ }^{19}$ Finally, a white powder rich in silica is obtained with a high surface area. ${ }^{20}$ Singh et al., ${ }^{21}$ Kalapathy et al. ${ }^{22}$ and Yalçin and Sevinç ${ }^{23}$ concluded that rice husk ash (RHA) is an excellent source of highly pure amorphous silica. Amorphous silica is a porous material, with a high superficial area and several applications in polymers, electronics, catalysis, ceramics, pharmaceuticals, manufacture of dental materials, thermal insulation, rubbers, fine ceramic powders and cement additives, and it is used in the industry of photoelectric materials such as thixotropic agents and filler compounds. ${ }^{19,24-26}$ Nowadays, silica from RH is prepared using several methods, including sol-gel, vapour-phase reaction, thermal decomposition technique, thermal pyrolysis, chemical precipitation and biotransformation method. ${ }^{12,20}$ However, these techniques are complex, expensive or require a large amount of energy to transform ash into silica. For this reason, low-cost methods for obtaining microsilica from RH should be developed. The ball milling method is not used widely in the synthesis of silica particles from RH. This technique has many advantages such as low cost, effectiveness, high purity of products, moderate temperature reaction, good process control, easy operation and reproducibility. $^{27}$

Several studies have focused on the production of microsilica and nanosilica particles by expensive techniques such as chemical and biological methods; $;^{12,28,29}$ however, more work is required that leads to the implementation of low-cost methods. The purpose of this work was to obtain silica from RH and then convert it into microsilica particles through mechanical ball milling, which is a versatile and low-cost technique. The purity of the silica and the change in the morphology and the structural properties during the reduction of particle size in relation to the grinding time were studied. Many researchers have studied alternative uses for this waste during the last decade. ${ }^{22}$ Some research studies have shown that ash is used as a source of highly pure amorphous silica. $^{23-26,30}$ It is also used for the production of highperformance silicon and its derivative compounds such as silicon carbide, silicon nitride, silicon tetrachloride and zeolites. ${ }^{12}$

\section{Experimental procedure}

\subsection{Microsilica synthesis}

\subsubsection{RH incineration}

RH was collected from the central zone of Colombia (Tolima). $\mathrm{RH}$ was washed four times with distilled water to remove impurities and other contaminants, and then it was dried in the oven at $100^{\circ} \mathrm{C}$ for $3 \mathrm{~h}$. The $\mathrm{RH}$ was then burnt in a furnace; the temperature was raised at a rate of $5^{\circ} \mathrm{C} / \mathrm{min}$ to $400^{\circ} \mathrm{C}$ and was maintained isothermally for $1 \mathrm{~h}$ to remove organic material. Then, the temperature was increased to $700^{\circ} \mathrm{C}$ and was maintained isothermally for $1 \mathrm{~h}$ to increase the amount of silica oxide by reducing the carbonaceous materials. ${ }^{27}$

\subsubsection{Elimination of inorganic impurities}

For the chemical treatment, distilled water, sulfuric acid $\left(\mathrm{H}_{2} \mathrm{SO}_{4}\right)$, nitric acid $\left(\mathrm{HNO}_{3}\right)$ or hydrochloric acid $(\mathrm{HCl})$ was used. The acids were purchased from Colombia Bioquigen Ltd and were analytically pure. RHA was leached to remove impurities through a chemical reaction between the acid and the metallic impurities. These reacted metals are leached from the acid solution during filtration. ${ }^{31}$ Ash samples of $15.0 \mathrm{~g}$ were added to $250 \mathrm{ml}$ of hydrochloric acid, nitric acid or sulfuric acid solution $(1 \cdot 0 \mathrm{M})$ and stirred for $1 \mathrm{~h}$ at $90^{\circ} \mathrm{C}$. The obtained paste was washed four times with distilled water, filtered and dried in a conventional oven at $100^{\circ} \mathrm{C}$ for $3 \mathrm{~h}$. After the leaching process, a white powder rich in silica was obtained, as can be seen in Figure 1.

\subsubsection{Mechanical ball milling}

A unitised jar mill model 753RM, commercialised by U. S. Stoneware, equipped with a ceramic container and $20 \mathrm{~mm}$ dia. ceramic cylinders as grinding media were used. A cylinders/ powder ratio of 10:1 was used at a frequency of 100 revolutions per minute for the mechanical ball milling process. Samples were prepared with different milling times and compared with a control sample. Table 1 shows the experimental conditions of this process.

\subsection{Methods of characterisation}

\subsubsection{Thermogravimetric analysis}

The analysis of the thermal properties of the RH was performed using a TGA Q500 instrument (TA Instruments, USA). Samples
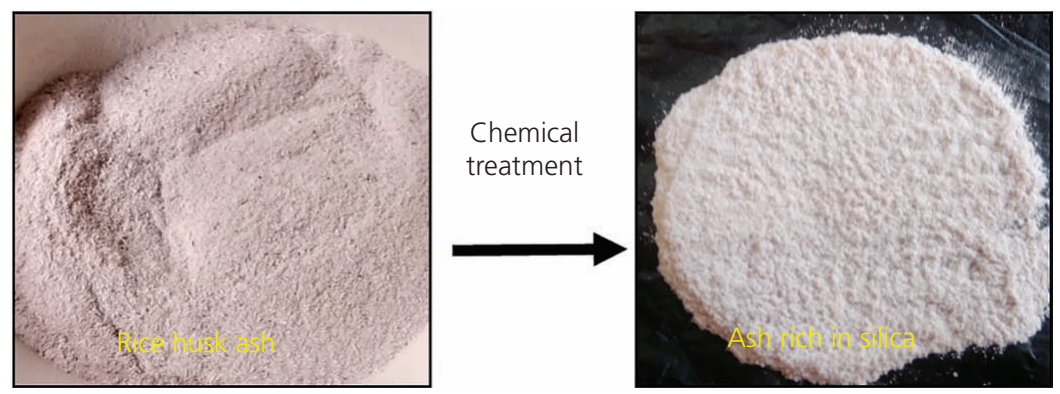

Figure 1. Photographs of the transformation of the ash with the acid leaching process: (a) RHA; (b) white ash with high content of silica 
Table 1. Mechanical ball milling experimental conditions

\begin{tabular}{|ccc|} 
Sample (ash) & Milling time: $\mathbf{h}$ & Label name \\
\hline 1 & 0 & $\mathrm{CO}$ \\
2 & 18 & $\mathrm{C} 18$ \\
3 & 36 & $\mathrm{C} 36$ \\
4 & 72 & $\mathrm{C} 72$
\end{tabular}

of $6 \cdot 5 \pm 0 \cdot 1 \mathrm{mg}$ were placed in a platinum crucible and heated at a heating rate of $10^{\circ} \mathrm{C} / \mathrm{min}$ from room temperature to $700^{\circ} \mathrm{C}$. The ramps were conducted under the dynamic air atmosphere $(60 \mathrm{ml} / \mathrm{min})$. The maximum rates of degradation and decomposition steps were determined through the peaks defined in a derivative curve. The mass loss associated with organic material content and residue was determined using the Universal Analysis 2000 TA software.

\subsubsection{X-ray fluorescence analysis}

X-ray fluorescence (XRF) was used in order to determine the chemical composition of RHA. Previously, the ash samples were dried at $105^{\circ} \mathrm{C}$ for $12 \mathrm{~h}$. Then, the powder samples were mixed with spectrometric wax (Merck \& Co.); a sample/wax ratio of 10:1 was used. The slurry was homogenised by means of stirring and compacted to generate $37 \mathrm{~mm}$ dia. pellets for the analysis. The semi-quantitative analysis was performed with the software SemiQ performing 11 scans to detect components, excluding the lighter elements (hydrogen $(\mathrm{H})$, carbon $(\mathrm{C})$, lithium $(\mathrm{Li})$, beryllium $(\mathrm{Be})$, boron $(\mathrm{B})$, nitrogen $(\mathrm{N})$, oxygen $(\mathrm{O})$ ) and transuranic ones. A Philips MagixPro PW-2440 XRF spectrometer equipped with a rhodium tube with a maximum power of $4 \mathrm{~kW}$ was used. The equipment has a sensitivity of 200 parts per million $(0.02 \%)$ in the detection of heavy metal elements. Table 2 shows the experimental conditions for the samples.

\subsubsection{Morphological analysis by scanning electron microscopy}

A Jeol JSM 5910 LV scanning electron microscope was used with $15.00 \mathrm{kV}$ electron acceleration voltage, in order to study the morphology of RHA. Prior to the analysis, the samples were fixed on copper $(\mathrm{Cu})$ specimens held on carbon adhesive tape. A gold layer approximately $20 \mathrm{~nm}$ thick was deposited by sputtering on ash surface to make it conductive.

\subsubsection{Structural analysis by X-ray diffraction}

Crystalline phases presented in RHA were identified using Rigaku diffractometer equipment, MiniFlex II, operated at room temperature and equipped with a copper $\mathrm{K} \alpha$ radiation source $(\lambda=$

Table 2. Experimental conditions for the acid leaching process for the RHA samples

\begin{tabular}{|ll} 
Sample & \multicolumn{1}{c}{ Conditions } \\
\hline 1 & Without leaching \\
2 & Leached with sulfuric acid \\
3 & Leached with nitric acid \\
4 & Leached with hydrochloric acid
\end{tabular}

$1 \cdot 540562 \AA$ ), and a $30 \mathrm{kV}$ and $15 \mathrm{~mA} \mathrm{X}$-ray source. Measurements were run from 5 and $70^{\circ}$ on a $2 \theta$ scale with a step size of $0.02 \%$ s. In order to find the percentage of crystallinity, the free version of the MDI Jade 5 software was used.

\section{Results and discussion}

\subsection{Thermogravimetric analysis}

Figure 2 shows the thermogravimetric analysis (TGA) curves, showing the amount of mass remaining from the combustion of the husk as a function of temperature. The derivative profile from differential thermal thermogravimetric analysis (DTGA) gives the rate of change of mass loss as the temperature rises. The thermograph of Figure 2 identifies three characteristic events in the decomposition process. The events were delimited with the help of the peaks in the DTGA derivative. Event 1 ranges from room temperature to $140^{\circ} \mathrm{C}$, event 2 between 150 and $350^{\circ} \mathrm{C}$ and event 3 between 350 and $500^{\circ} \mathrm{C}$. In the first stage (dehydration), the curve shows an initial weight loss of $5 \cdot 87 \%$. This loss can be interpreted as the elimination of physically adsorbed water by the porosity of the husk and external water bounded by surface tension. ${ }^{30}$ In the second stage, corresponding to the highest peak in DTGA, the active pyrolysis zone was identified. In this process, hemicellulose and cellulose are decomposed into small molecules and then released as gaseous volatiles. When this reaction is carried out, carbon and oxygen are removed from the polymer, and mainly carbon dioxide $\left(\mathrm{CO}_{2}\right)$ or carbon monoxide (CO) is released. ${ }^{30}$ In this process, $48.05 \%$ of the mass of the sample was removed. In the third stage, the so-called passive pyrolysis zone, $20 \cdot 14 \%$ of the mass was released due to the lignin combustion process. ${ }^{24,25}$ After $550^{\circ} \mathrm{C}$, the mass remains stable and the ash $(25 \cdot 57 \%)$ corresponds to the inorganic residue. The analysis of residue was done with XRF (reported in the following); the RHA consists mainly of silica. ${ }^{24}$

The temperature peak values represent the highest rate of change of mass for the three stages: $44 \cdot 13,304 \cdot 30$ and $425 \cdot 86^{\circ} \mathrm{C}$, respectively. The variables measured in TGA and DTGA are

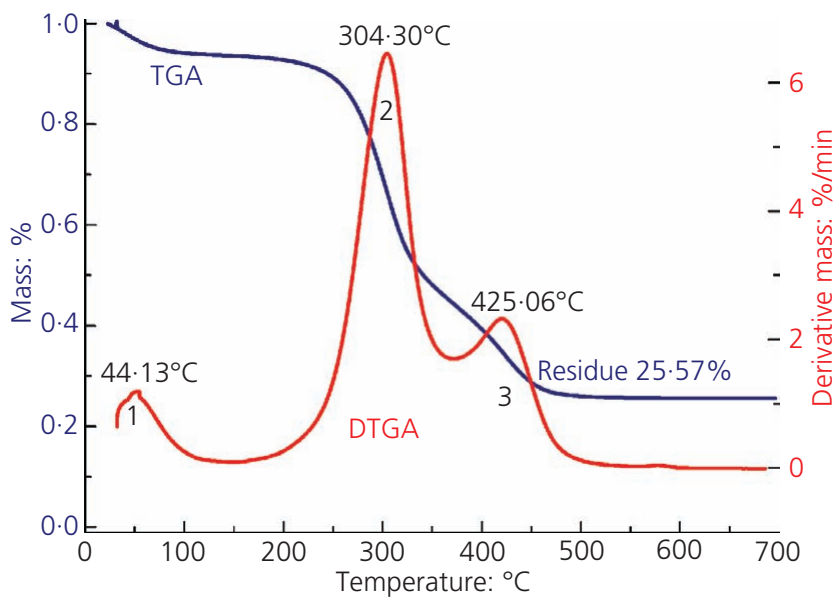

Figure 2. RH TGA and DTGA curves at air atmosphere at $10^{\circ} \mathrm{C} / \mathrm{min}$ 
Table 3. TGA/DTGA characterisation of the RH

\begin{tabular}{lccccc} 
& \multicolumn{2}{c}{ TGA values } & & DTGA & Identification \\
\cline { 2 - 3 } Event & Temperature range: ${ }^{\circ} \mathrm{C}$ & Weight loss: \% & & Maximum peak temperature: ${ }^{\circ} \mathrm{C}$ & Moisture/water elimination \\
\hline 1 & $25-140$ & $5 \cdot 87$ & & $44 \cdot 13$ & Hemicellulose and cellulose degradation \\
2 & $150-350$ & 20.05 & & 304.30 & Lignin degradation \\
3 & $350-500$ & 20.14 & & $425 \cdot 86$ &
\end{tabular}

summarised in Table 3. These values are in agreement with those from the studies of Pandey et al., ${ }^{30}$ who reported that the three main constituents of the lignocellulosic materials (hemicellulose, cellulose and lignin) are chemically active and decompose thermochemically at a temperature range between 150 and $500^{\circ} \mathrm{C}$. They also reported that the decomposition of hemicellulose starts first at a range between 150 and $350^{\circ} \mathrm{C}$, followed by the decomposition of cellulose between 275 and $350^{\circ} \mathrm{C}$. In addition, these two components contribute mainly to the formation of the volatile compounds, while lignin, whose decomposition occurs between 250 and $500^{\circ} \mathrm{C}$, is mainly responsible for the char portion of the product.

\subsection{Analysis of inorganic impurities}

The chemical composition of ash was obtained by XRF for four samples with different acid leaching processes. The results are shown in Table 4. The leaching process converts the metallic elements into soluble ions; then, these are removed during filtration. ${ }^{9}$ According to Table 4, the ash leached with acid presents an increase in its silica content and a reduction of impurities; the acid leaching process decreased the level of these oxides. Before the chemical treatment, the silica content in the ash was $93 \cdot 40 \%$. After the treatment, the content rose to $98.22 \%$; this indicates that the impurities represented mainly in metallic oxides were eliminated. In relation to the effectiveness of the solvent for removing impurities, it can be inferred that there are no significant differences among them.

\subsection{Morphological analysis}

The effect of milling time on the morphology and particle size of RHA was investigated. Figure 3 shows the micrographs of the four samples with milling times of $0,18,36$ and $72 \mathrm{~h}$ at $\times 100, \times 1000$ and $\times 20000$ magnifications, respectively. The effect of milling time on the morphology and particle size of RHA was investigated. The scanning electron microscopy (SEM) images of Figure 3 show the effect of milling time for three magnifications. The control sample (C0) showed larger grains, even with particle agglomerates that reach approximately $10 \mu \mathrm{m}$. On the other hand, with the increase in milling time (from 18 to $72 \mathrm{~h}$ ), the size of silica particles decreased: even microparticles measuring less than $3 \mu \mathrm{m}$ can be observed. A detailed view at $\times 40000$ magnification of the three samples $\mathrm{C} 18$, $\mathrm{C} 36$ and C72 are shown in Figure 4. Some agglomerates of silica micron and submicron particles and the formation of cumuli among the particles can be seen. The effect of milling time on the reduction in the mean particle size is again observed. For both milling times of 18 and $36 \mathrm{~h}$, the particles reach a size lower than $3 \mu \mathrm{m}$, while the sample with a milling time of $72 \mathrm{~h}$ (C72) presents a finer grain size that is even smaller than $1 \mu \mathrm{m}$; there are also some isolated particles in the submicron (nano) size (see Figure 5). These results agree with those of Liou et al. ${ }^{32}$

A more detailed view at $\times 80000$ magnification of $\mathrm{C} 72$ is presented in Figure 5. The particles, which are presented as clusters, have a size less than $1.0 \mu \mathrm{m}$; this phenomenon can be associated with electrostatic attraction or van der Waals forces. ${ }^{33}$ These results clearly show that the particle size decreased as the mechanical milling time increased; microparticles and even agglomerates of silica nanoparticles can be obtained. Increasing the milling time (from 0 to $72 \mathrm{~h}$ ) reduces significantly the particle size in $\mathrm{C} 18, \mathrm{C} 36$ and $\mathrm{C} 72$ samples, because the system is subjected for longer to the collisions, intensive fracturing and welding generated in the milling process. Mechanical ball milling is shown to be effective for reducing the particle mean size of the silica.

Table 4. Chemical compositions of RHA with and without chemical treatment

\begin{tabular}{|c|c|c|c|c|}
\hline $\begin{array}{l}\text { Element and/or } \\
\text { compound }\end{array}$ & $\begin{array}{l}\text { Without chemical } \\
\text { treatment: } \%\end{array}$ & $\begin{array}{l}\text { Leached with sulfuric } \\
\text { acid: } \%\end{array}$ & $\begin{array}{l}\text { Leached with nitric } \\
\text { acid: } \%\end{array}$ & $\begin{array}{l}\text { Leached with hydrochloric } \\
\text { acid: } \%\end{array}$ \\
\hline Silicon dioxide $\left(\mathrm{SiO}_{2}\right)$ & $93 \cdot 40$ & $98 \cdot 22$ & 98.44 & $98 \cdot 48$ \\
\hline Calcium oxide & 0.70 & 0.27 & 0.26 & 0.25 \\
\hline Potassium oxide & 0.68 & 0.71 & 0.63 & 0.60 \\
\hline Phosphorus trioxide $\left(\mathrm{P}_{2} \mathrm{O}_{3}\right)$ & 0.59 & 0.05 & 0.04 & 0.06 \\
\hline Magnesium oxide & 0.26 & $0 \cdot 21$ & $0 \cdot 22$ & $0 \cdot 20$ \\
\hline Aluminium oxide & $0 \cdot 21$ & $0 \cdot 14$ & $0 \cdot 11$ & $0 \cdot 10$ \\
\hline Manganese oxide & $0 \cdot 14$ & $0 \cdot 10$ & $0 \cdot 10$ & $0 \cdot 10$ \\
\hline Iron (III) oxide $\left(\mathrm{Fe}_{2} \mathrm{O}_{3}\right)$ & 0.09 & $0 \cdot 10$ & 0.09 & 0.08 \\
\hline Sulfur trioxide $\left(\mathrm{SO}_{3}\right)$ & 0.07 & $0 \cdot 10$ & 0.04 & 0.05 \\
\hline Chlorine (Cl) & 0.06 & 0.06 & 0.04 & 0.05 \\
\hline $\mathrm{Na}_{2} \mathrm{O}_{3}$ & 0.02 & 0.03 & 0.02 & 0.02 \\
\hline Others & $3 \cdot 78$ & 0.01 & 0.01 & 0.01 \\
\hline
\end{tabular}


Green Materials

Volume 6 Issue GMAT1
Synthesis and characterisation of

submicron silica particles from rice husk

Hincapié-Rojas, Pineda-Gomez and Rosales-Rivera

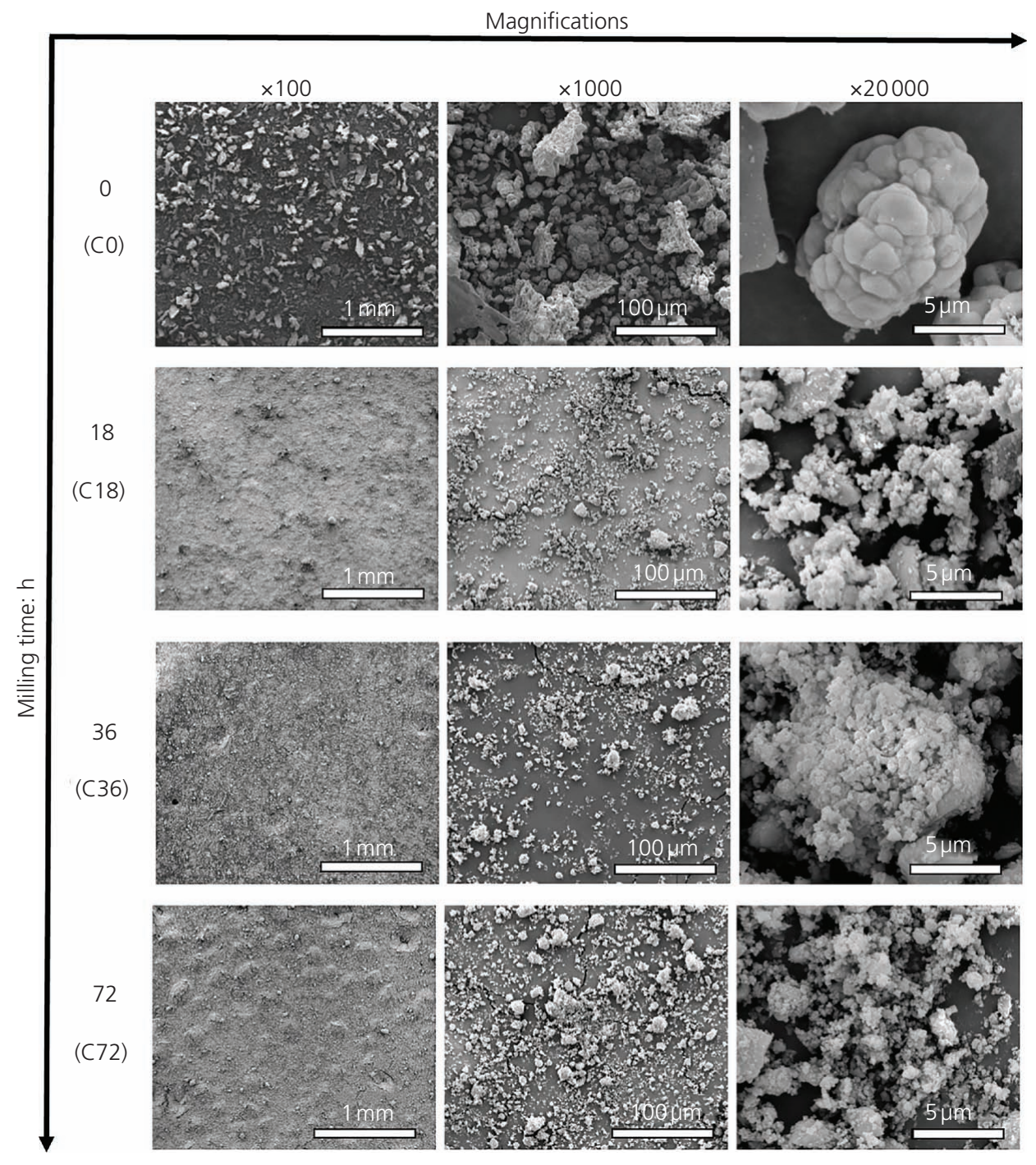

Figure 3. SEM micrographs at $\times 100, \times 1000$ and $\times 20000$ of ash samples leached with nitric acid, for different milling times

\subsection{Structural analysis by X-ray diffraction}

The X-ray diffraction (XRD) patterns of the RHA for different milling times $(0,18,36$ and $72 \mathrm{~h})$ are shown in Figure 6. Silica oxide was the principal phase identified thought the patterns; the arrows in the figure correspond to the localisation of main diffracted peaks of silica oxide. These results were compared with database code AMCSD 0001629 of silica oxide. The most prominent peak is at $2 \theta=22 \cdot 01^{\circ}$. On the other hand, Figure 6

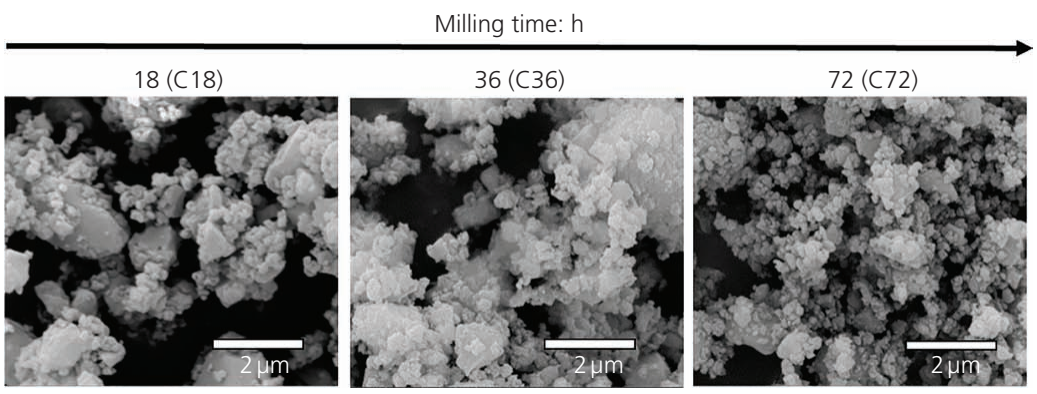

Figure 4. SEM micrographs at $\times 40000$ of ash samples leached with nitric acid for different milling times 
Synthesis and characterisation of

submicron silica particles from rice husk

Hincapié-Rojas, Pineda-Gomez and Rosales-Rivera

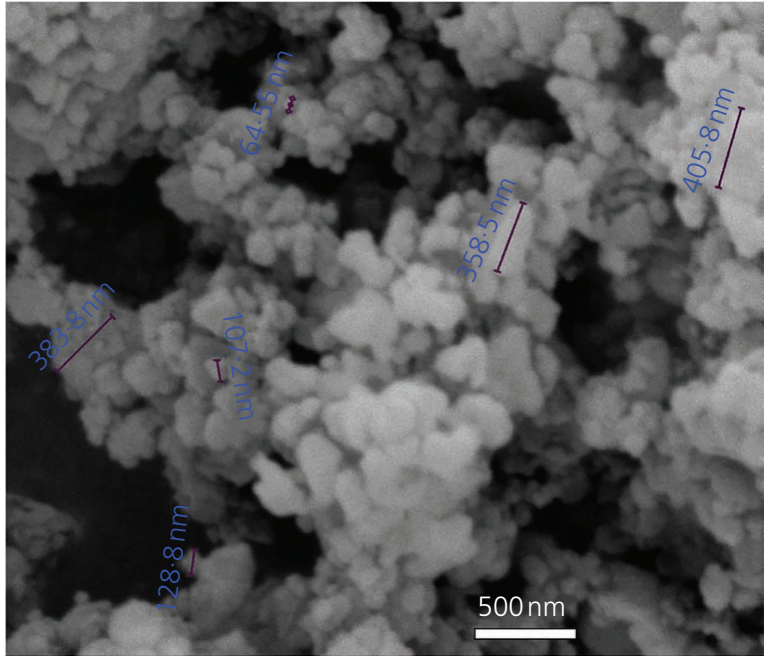

Figure 5. SEM micrographs at $\times 80000$ of ash samples leached with nitric acid with $72 \mathrm{~h}$ of mechanical ball milling

also shows that peaks at high angles tend to disappear with increasing milling time. This fact is clearly noticed when comparing the patterns corresponding to 0 and $72 \mathrm{~h}$ of milling. The effect of milling was corroborated. For 18,36 and $72 \mathrm{~h}$ of milling, the peaks corresponding to the planes (113) and (212) disappeared, and the more prominent peak (101) was widened and became less intense; other peaks ((111), (102), (200), (301)) were also attenuated, which indicates that the crystallinity of the silica was reduced as a consequence of the milling process.

In order to determine the influence of milling time on the structure, Figure 7(a) shows the peak [101] for the samples $\mathrm{C} 0$, $\mathrm{C} 36$ and $\mathrm{C} 72$. It is clear that the intensity decreases and the width

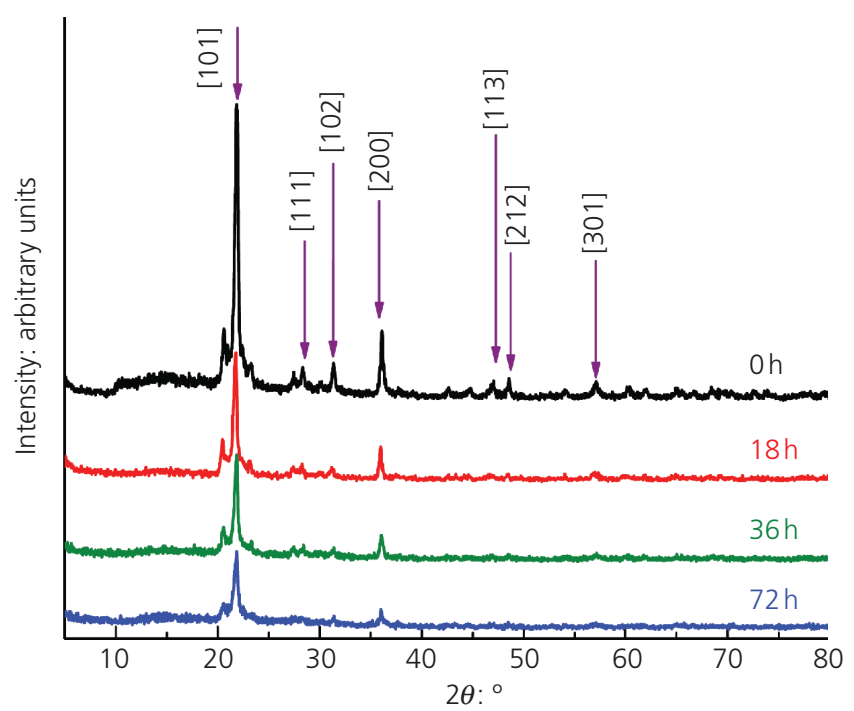

Figure 6. XRD patterns of RHA for different milling times peak increases as the milling times were increased. The reduction in the intensity can be correlated with the structural changes in the silica, and an increase in stacking faults and structural disorder widens the XRD peaks. This widening is also related to the reduction in the particle size as shown in SEM images. To determine the influence of the milling time on the structure, the changes in the intensity and the full width at half maximum (FWHM) of the peak can be correlated with the structural changes in the sample. Mechanical milling always introduces stress that manifests itself with the widening of the diffraction peaks. The values corresponding to the FWHM were obtained using a Gaussian model and are shown in Figure 7(b).

The samples with $72 \mathrm{~h}$ of milling time showed the higher value of FWHM. Two facts can be attributed to this widening: the

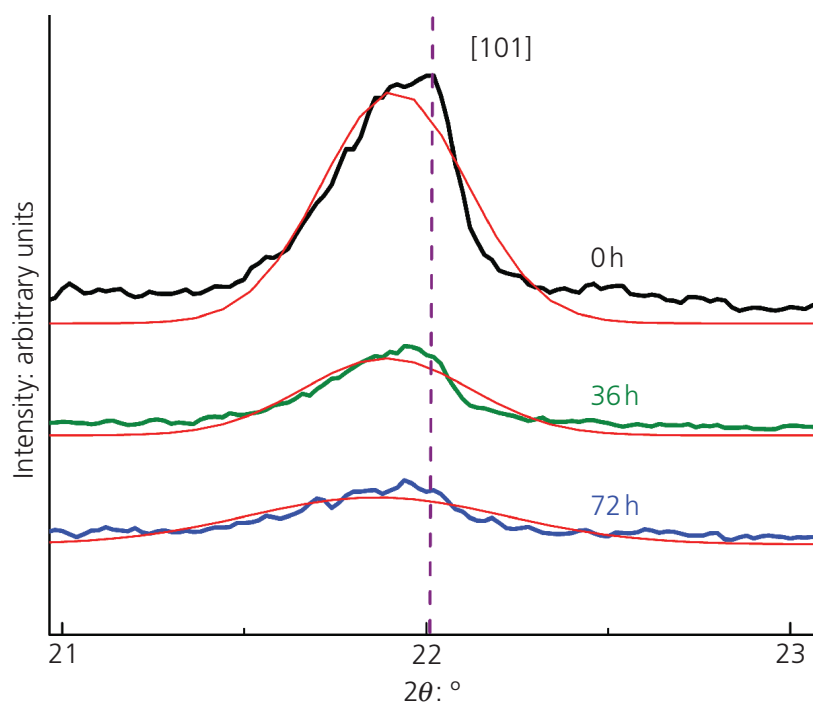

(a)

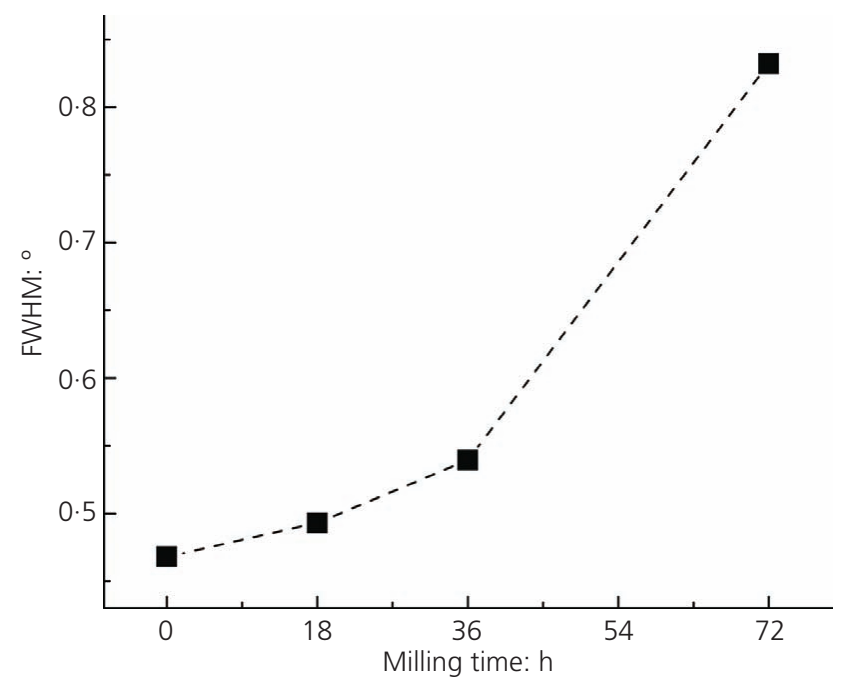

(b)

Figure 7. (a) The peak [101] and its Gaussian approach of the samples at different milling times. (b) Full width at half-maximum (FWHM) curve as a function of milling time 
Synthesis and characterisation of

submicron silica particles from rice husk

Hincapié-Rojas, Pineda-Gomez and Rosales-Rivera reduction in particle size and the mechanical stress in the material. It can be interpreted as a structural distortion effect, an increase in hardness and density of point defects originated by the collisions, which affect the crystallinity, and grain boundary mobility; this fact is more evident for a higher milling time. ${ }^{34}$

Finally, the crystallinity percentage values were calculated in order to determine the effect of mechanical milling. Values of $33 \cdot 5,31 \cdot 9,30 \cdot 7$ and $28.5 \%$ were obtained for samples $\mathrm{C} 0, \mathrm{C} 18$, $\mathrm{C} 36$ and $\mathrm{C} 72$, respectively. The FWHM changes showed that milling time changed the structure because the high FWHM is related to a lower crystallinity of the samples.

\section{Conclusion}

In this work, a versatile and efficient method for obtaining submicron silica particles from the incineration of $\mathrm{RH}$ and mechanical milling of its ash was developed. TGA showed that the decomposition of RH occurred in three stages corresponding to water removal, active pyrolysis and passive pyrolysis. Above $550^{\circ} \mathrm{C}$, the mass stabilised and a residue was obtained. XRF analysis showed that the residue was essentially silica. The acid treatment proved to be effective for removing impurities; this process generated increases of $5 \%$ in ash purity. The predominant structural phase shown by XRD was silica. The attenuation of peaks in larger $2 \theta$ angles and a decrease in the intensity of the main peak at $2 \theta=22 \cdot 01^{\circ}$ were observed. The crystallinity degree was reduced as a consequence of the milling process. The SEM images showed that at $72 \mathrm{~h}$ of milling, agglomerates of submicron silica particles with a diameter smaller than $1.0 \mu \mathrm{m}$ were obtained. $\mathrm{RH}$ is considered a natural material source of silica which can be used as an additive in cement and provide added value to this abundant waste product.

\section{Acknowledgements}

The authors thank Professor E. R. Parra and Professor P. J. Arango for XRD and G. A. Bolaños for SEM studies. This work was supported by Dirección de Investigaciones de la Sede Manizales (Hermes Project 30955) Universidad Nacional de Colombia, Sede Manizales and Colciencias.

\section{REFERENCES}

1. Food and Agriculture Organization of the United Nations (2016) Seguimiento del mercado del arroz de la FAO. Food and Agriculture Organization of the United Nations, Rome, Italy (in Spanish).

2. Prasetyoko D, Ramli Z, Endud S, Hamdan H and Sulikowski B (2006) Conversion of rice husk ash to zeolite beta. Waste Management 26(10): 1173-1179.

3. Della VP, Kühn I and Hotza D (2002) Rice husk ash as an alternate source for active silica production. Materials Letters 57(4): 818-821.

4. An D, Guo Y, Zhu Y and Wang Z (2010) A green route to preparation of silica powders with rice husk ash and waste gas. Chemical Engineering Journal 162(2): 509-514.

5. Chindaprasirt P, Kanchanda P, Sathonsaowaphak A and Cao HT (2007) Sulfate resistance of blended cements containing fly ash and rice husk ash. Construction and Building Materials 21(6): 1356-1361.
6. Chindaprasirt P, Jaturapitakkul C and Rattanasak U (2009) Influence of fineness of rice husk ash and additives on the properties of lightweight aggregate. Fuel 88(1): 158-162.

7. Ganesan K, Rajagopal K and Thangavel K (2008) Rice husk ash blended cement: assessment of optimal level of replacement for strength and permeability properties of concrete. Construction and Building Materials 22(8): 1675-1683.

8. Nehdi M, Duquette J and El Damatty A (2003) Performance of rice husk ash produced using a new technology as a mineral admixture in concrete. Cement and Concrete Research 33(8): 1203-1210.

9. Liou T and Wu S (2010) Kinetics study and characteristics of silica nanoparticles produced from biomass-based material. Industrial \& Engineering Chemistry Research 49(18): 8379-8387.

10. Zheng JL and Kong YP (2010) Spray combustion properties of fast pyrolysis bio-oil produced from rice husk. Energy Conversion and Management 51(1): 182-188.

11. Wang G, Wang D, Kuang S, Xing W and Zhuo S (2014) Hierarchical porous carbon derived from rice husk as a low-cost counter electrode of dye-sensitized solar cells. Renewable Energy 63: 708-714.

12. Tolba GMK, Barakat NAM, Bastaweesy AM et al. (2015) Effective and highly recyclable nanosilica produced from the rice husk for effective removal of organic dyes. Journal of Industrial and Engineering Chemistry 29: 134-145.

13. Sierra Aguilar J (2009) Alternativas de aprovechamiento de la cascarilla de arroz en Colombia. MSCE thesis, Universidad de Sucre, Sincelejo, Colombia (in Spanish).

14. Cobreros C, Reyes-Araiza JL, Manzano-Ramírez A et al. (2015) Barley straw ash: pozzolanic activity and comparison with other natural and artificial pozzolans from Mexico. BioResources 10(2): 3757-3774.

15. Carmona VB, Oliveira RM, Silva WTL, Mattoso LHC and Marconcini JM (2013) Nanosilica from rice husk: extraction and characterization. Industrial Crops and Products 43(1): 291-296.

16. Shen $Y$, Zhao P and Shao Q (2014) Porous silica and carbon derived materials from rice husk pyrolysis char. Microporous and Mesoporous Materials 188: 46-76.

17. Zhang Z, He W, Zheng J, Wang G and Ji J (2016) Rice husk ash-derived silica nanofluids: synthesis and stability study. Nanoscale Research Letters 11(1): 502.

18. Sun L and Gong K (2001) Silicon-based materials from rice husks and their applications. Industrial \& Engineering Chemistry Research 40(25): 5861-5877.

19. Deiana C, Granados D, Venturini R et al. (2008) Activated carbons obtained from rice husk: influence of leaching on textural parameters. Industrial \& Engineering Chemistry Research 47(14): $4754-4757$.

20. Zhang H, Zhao X, Ding X et al. (2010) A study on the consecutive preparation of d-xylose and pure superfine silica from rice husk. Bioresource Technology 101(4): 1263-1267.

21. Singh D, Kumar R, Kumar A and Rai KN (2008) Synthesis and characterization of rice husk silica, silica-carbon composite and $\mathrm{H}_{3} \mathrm{PO}_{4}$ activated silica. Cerâmica 54(330): 203-212.

22. Kalapathy U, Proctor A and Shultz J (2003) Silicate thermal insulation material from rice hull ash. Industrial \& Engineering Chemistry Research 42(1): 46-49.

23. Yalçin N and Sevinç V (2001) Studies on silica obtained from rice husk. Ceramics International 27(2): 219-224.

24. Kamath SR and Proctor A (1998) Silica gel from rice hull ash: preparation and characterization. Cereal Chemistry 75(4): 484-487.

25. Liou TH (2004) Evolution of chemistry and morphology during the carbonization and combustion of rice husk. Carbon 42(4): 785-794.

26. Pijarn N, Jaroenworaluck A, Sunsaneeyametha W and Stevens R (2010) Synthesis and characterization of nanosized-silica gels formed under controlled conditions. Powder Technology 203(3): 462-468. 
27. Liou TH (2004) Preparation and characterization of nano-structured silica from rice husk. Materials Science and Engineering: A 364(1-2): 313-323.

28. Salavati-Niasari M, Javidi J and Dadkhah M (2013) Ball milling synthesis of silica nanoparticle from rice husk ash for drug delivery application. Combinatorial Chemistry \& High Throughput Screen 16(6): 458-462.

29. Bansal V, Ahmad A and Sastry M (2006) Fungus-mediated biotransformation of amorphous silica in rice husk to nanocrystalline silica. Journal of the American Chemical Society 128(43): 14059-14066.

30. Pandey S, Mewada A, Thakur M and Pillai S (2014) Synthesis of mesoporous silica oxide/C-dot complex (meso-SiO $2 / \mathrm{C}$-dots)) using pyrolysed rice husk its application in bioimaging. RSC Advances 4(20): 1174-1179

31. Estevez M, Vargas S, Castaño VM and Rodriguez R (2009) Silica nano-particles produced by worms through a bio-digestion process of rice husk. Journal of Non-crystalline Solids 355(14-15): 844-850.

32. Liou TH, Chang FW and Lo JJ (1997) Pyrolysis kinetics of acidleached rice husk. Industrial \& Engineering Chemistry Research 36(3): 568-573.

33. Mansaray KG and Ghaly AE (1998) Thermal degradation of rice husks in nitrogen atmosphere. Bioresource Technology 65(1-2): 13-20.

34. Ruksudjarit A and Rujijanagul G (2008) Synthesis of $\mathrm{SiO}_{2}$ nanopowder from rice husk ash. Advanced Materials Research 55-57: 649-652.

\section{How can you contribute?}

To discuss this paper, please submit up to 500 words to the journal office at journals@ice.org.uk. Your contribution will be forwarded to the author(s) for a reply and, if considered appropriate by the editor-in-chief, it will be published as a discussion in a future issue of the journal.

ICE Science journals rely entirely on contributions from the field of materials science and engineering. Information about how to submit your paper online is available at www.icevirtuallibrary.com/page/authors, where you will also find detailed author guidelines. 